\title{
Downstream separation and purification of succinic acid from fermentation broths using spent sulphite liquor as feedstock
}

Alexandri, Maria; Vlysidis, Anestis; Papapostolou, Harris; Tverezovskaya, Olga; Tverezovskiy, Viacheslav; Kookis, Ioannis K.; Koutinas, Apostolis

\section{Separation and Purification Technology}

\section{DOI:}

10.1016/j.seppur.2018.08.061

Published: 31/01/2019

Peer reviewed version

Cyswllt i'r cyhoeddiad / Link to publication

Dyfyniad o'r fersiwn a gyhoeddwyd / Citation for published version (APA):

Alexandri, M., Vlysidis, A., Papapostolou, H., Tverezovskaya, O., Tverezovskiy, V., Kookis, I. K., \& Koutinas, A. (2019). Downstream separation and purification of succinic acid from fermentation broths using spent sulphite liquor as feedstock. Separation and Purification Technology, 209, 666-675. https://doi.org/10.1016/j.seppur.2018.08.061

\footnotetext{
Hawliau Cyffredinol / General rights

Copyright and moral rights for the publications made accessible in the public portal are retained by the authors and/or other copyright owners and it is a condition of accessing publications that users recognise and abide by the legal requirements associated with these rights. study or research.

- Users may download and print one copy of any publication from the public portal for the purpose of private

- You may not further distribute the material or use it for any profit-making activity or commercial gain

- You may freely distribute the URL identifying the publication in the public portal?
}

Take down policy

If you believe that this document breaches copyright please contact us providing details, and we will remove access to the work immediately and investigate your claim. 


\section{Accepted Manuscript}

Downstream separation and purification of succinic acid from fermentation broths using spent sulphite liquor as feedstock

Maria Alexandri, Anestis Vlysidis, Harris Papapostolou, Olga Tverezovskaya, Viacheslav Tverezovskiy, Ioannis K. Kookos, Apostolis Koutinas

PII: S1383-5866(18)30152-7

DOI: https://doi.org/10.1016/j.seppur.2018.08.061

Reference: SEPPUR 14882

To appear in: Separation and Purification Technology

Received Date: 14 January 2018

Revised Date: 16 August 2018

Accepted Date: 29 August 2018

Please cite this article as: M. Alexandri, A. Vlysidis, H. Papapostolou, O. Tverezovskaya, V. Tverezovskiy, I.K. Kookos, A. Koutinas, Downstream separation and purification of succinic acid from fermentation broths using spent sulphite liquor as feedstock, Separation and Purification Technology (2018), doi: https://doi.org/10.1016/j.seppur. 2018.08.061

This is a PDF file of an unedited manuscript that has been accepted for publication. As a service to our customers we are providing this early version of the manuscript. The manuscript will undergo copyediting, typesetting, and review of the resulting proof before it is published in its final form. Please note that during the production process errors may be discovered which could affect the content, and all legal disclaimers that apply to the journal pertain. 


\section{Downstream separation and purification of succinic acid from fermentation broths using spent sulphite liquor as feedstock}

Maria Alexandri ${ }^{1,2}$, Anestis Vlysidis ${ }^{1,3}$, Harris Papapostolou ${ }^{1}$, Olga Tverezovskaya ${ }^{4}$, Viacheslav Tverezovskiy ${ }^{4}$, Ioannis K. Kookos ${ }^{5}$, and Apostolis Koutinas ${ }^{1 *}$

${ }^{1}$ Department of Food Science and Human Nutrition, Agricultural University of Athens, Iera Odos 75, Athens 11855, Greece

${ }^{2}$ Department of Bioengineering, Leibniz Institute for Agricultural Engineering and Bioeconomy (ATB), Max-Eyth Allee 100, Potsdam-Bornim, 14469, Germany

${ }^{3}$ School of Chemical Engineering, National Technical University, Iroon Polytechneiou 9, Zografou 157 80, Athens, Greece

${ }^{4}$ BioComposites Centre, Bangor University, Deiniol Road, Bangor, Gwynedd LL57 2UW, United Kingdom

${ }^{5}$ Department of Chemical Engineering, University of Patras, Rio 26504, Patras, Greece

* Corresponding author (akoutinas@aua.gr) 


\begin{abstract}
Spent sulphite liquor produced as side stream from sulphite pulping of Eucalyptus globulus hardwood could be used for the separation of lignosulphonates by nanofiltration in the retentate stream and succinic acid production via fermentation of the permeate stream by Actinobacillus succinogenes or Basfia succiniciproducens. The potential integration of this process in conventional pulp mills towards the development of a novel biorefinery is dependent on the efficient downstream separation of succinic acid crystals at high yield and purity. This study focuses on the evaluation of five downstream separation processes, namely calcium precipitation, direct crystallisation using acidification or cation-exchange resins, salting-out and reactive extraction, for the purification of succinic acid from crude fermentation broths. Reactive extraction using trioctylamine in 1-hexanol and direct crystallisation coupled with cation-exchange resins led to succinic acid recovery yields of $73 \%$ and $79 \%$, respectively. ${ }^{1} \mathrm{H}-\mathrm{NMR}$ analysis showed that these downstream separation processes led to succinic acid crystal purities of $c a 98.5 \%$ for reactive extraction and higher than $99 \%$ for the direct crystallisation method coupled with cation-exchange resins with no detectable acetic acid content when re-crystallisation was employed. It has been demonstrated that succinic acid produced via fermentation using side streams from pulp and paper mills could be separated at high purity and yield from crude fermentation broths rendering feasible its utilisation for poly(butylene succinate) production.
\end{abstract}

Keywords: succinic acid, spent sulphite liquor, downstream separation process, Basfia succiniciproducens, Actinobacillus succinogenes 


\section{Introduction}

Succinic acid is an important platform chemical with various industrial uses as it is a precursor for the production of numerous products, such as 1,4-butanediol, resins, coatings, pigments and many others [1]. Succinic acid is conventionally produced in the petrochemical industry via hydrogenation of maleic anhydride followed by hydration or direct hydrogenation of maleic acid, in a process that requires heavy metals as catalysts, organic solvents and high temperature and pressure [2]. However, in the last decade, it is also produced by biological means. The market for bio-based succinic acid has potential to reach a capacity of $600,000 \mathrm{t}$ by 2020 [3].

It has been demonstrated that spent sulphite liquor (SSL), a byproduct stream from the pulp and paper industry, can be used as fermentation feedstock for bio-based succinic acid production [4-7]. SSL is produced from the acidic sulphite pulping process and is rich in sugar monomers (mainly xylose) and lignosulphonates (LS). LS are products of lignin degradation and together with phenolic compounds present in SSL are inhibitory compounds in fermentation processes [4]. SSL constitutes an important feedstock for the bio-economy era as its annual production reaches 90 billion liters [8]. The combination of phenolic extraction followed by nanofiltration of SL for the removal of LS led to the production of a sugar-rich permeate that was used as fermentation medium for the production of $39 \mathrm{~g} / \mathrm{L}$ succinic acid using the bacterial strain Basfia succiniciproducens [5]. The efficient production of succinic acid in a crude fermentation feedstock should be combined with the efficient recovery of succinic acid crystals at high purity and yield [9]. High recovery yields are required for the development of cost competitive bio-based succinic acid production processes. High purities are required especially for the production of biopolymers, such as the poly(butylene succinate). The fermentation broth occurred from cultures carried out on SSL-based media is 
a multicomponent stream the composition of which could vary in wide proportions and thus succinic acid separation at high purity and yield is a challenging task.

The presence of monocarboxylic acids, such as acetic and formic acid that are produced as by-products during fermentation, inhibit the polymerisation process [10]. They act as chain stoppers during polymerisation preventing the polymer reaching high molecular weight, even if they are present in very low concentrations. For high quality and commercially viable poly(butylene succinate), its average molecular weight should be at least from $100 \mathrm{kDa}$ to $200 \mathrm{kDa}$ [11]. Poly(butylene succinate) with molecular weight of $200 \mathrm{kDa}$ contains about 1160 units of succinic acid in an average chain. To reach this chain length, monomeric succinic acid should have concentration of the impurities capable to be chain stoppers of less than $0.09 \mathrm{~mol} \%$. The presence of a small amount of di-acids (e.g. maleic acid) or hydroxy-acids (such as lactic acid, 2- or 3-hydroxybutyric acid, etc.) should not affect the polymer significantly, as their incorporation into the growing poly(butylene succinate) chain does not stop the polymerisation. Therefore, it is important to develop an efficient downstream separation process (DSP) for the removal of impurities originated from both the SSL-based media and the microbial metabolism leading to succinic acid crystals with purity sufficient for further polymerisation, but not excessively prohibitive in costs.

Many DSP have been evaluated in the literature (e.g. calcium precipitation, reactive extraction, electrodialysis, and crystallisation coupled with acidification of succinate salts) towards the separation and purification of succinic acid [11-17]. In the traditional calcium precipitation process, $\mathrm{Ca}(\mathrm{OH})_{2}$ is added in excess in order to precipitate succinic acid in the form of calcium succinate. Succinic acid is then released after the addition of $\mathrm{H}_{2} \mathrm{SO}_{4}$. This process results in high amounts of $\mathrm{CaSO}_{4}$ and relatively low purities of the final product [12]. Reactive extraction using amines in an organic solvent has been reported in literature-cited publications [13-15]. In DSP based on electrodialysis, succinic acid is separated from the non- 
ionised compounds that are present in the fermentation broth through ion-exchange membranes [16]. Crystallisation is based on the precipitation of succinic acid at low temperatures and it is mainly the final step after acidification or treatment with resins and evaporation $[9,17]$. The highest succinic acid recovery yield $(89.5 \%)$ and purity $(99 \%)$ have been achieved by Lin et al. [17] when fermentation broths of the bacterial strain Actinobacillus succinogenes cultivated on wheat-derived hydrolysate were used. Another recovery process is salting-out, which is applied in order to separate a hydrophilic compound from an aqueous solution using an organic solvent as an extractant and an inorganic salt as the salting-out reagent at appropiate concentrations [18]. Furthermore, Orjuela et al. [19,20] proposed simultaneous acidification and esterification of succinic acid from pure solutions and fermentation broths, that is recovered as a solution of free succinic acid, monoethyl succinate and diethyl succinate in ethanol, reporting around $95 \%$ recovery for both media. The number of unit operations employed in DSP for the purification of succinic acid could be achieved by developing coupled fermentation-separation system [21] or conducting fermentations with genetically engineered yeast strains at low $\mathrm{pH}[22]$.

The development of economically viable bioprocesses for succinic acid production can be achieved through refining of renewable resources including the production of value-added co-products. Biorefinery development based on SSL will generate fermentation broths with additional impurities, besides fermentation by-products and unconsumed nutrients. SSL is a low-value industrial side stream that can be fractionated into phenolic compounds and lignosulphonates, prior to fermentation of the remaining hemicellulose derived sugars to succinic acid [5]. This study focuses on the evaluation of five DSP in order to identify the most efficient process for the separation and purification of succinic acid from crude fermentation broths where nanofiltrated SSL was used as feedstock. The calcium precipitation method, salting-out, reactive extraction and direct crystallisation using acidification or cation- 
exchange resins have been tested on simulated and actual fermentation broths. Succinic acid production was carried out by the bacterial strains A. succinogenes and B. succiniciproducens.

\section{Materials \& Methods}

\subsection{Chemicals, microorganisms and spent sulphite liquor}

The bacterial strains A. succinogenes $130 \mathrm{Z}$ (DSM 22257) and B. succiniciproducens JF 4016 (DSM 22022) were purchased from Leibniz Institute DSMZ-German Collection of Microorganisms and Cell Cultures. Preservation of the microorganisms, strain precultures and fermentation conditions for succinic acid production were previously described $[5,23]$.

The chemicals used in this study were purchased from Sigma-Aldrich. The thick SSL used in fermentation processes after pretreatment and recovered LS from the thick SSL stream were supplied by Sniace S.A. (Torrelavega, Spain). The LS were added in synthetic solutions in order to formulate simulated fermentation media and thus evaluate the separation of succinic acid by different DSP. The SSL was derived via the acidic sulphite pulping process using the hardwood Eucalyptus globulus and dolomite. The composition of the thick SSL (e.g. sugars, LS, phenolics, dry matter) used in this study has been presented by Alexandri et al. [5].

\subsection{Evaluation of crystallisation duration}

A solution containing $190 \mathrm{~g} / \mathrm{L}$ of commercial succinic acid was prepared and heated to $80{ }^{\circ} \mathrm{C}$ in order to achieve complete dissolution. It was subsequently placed in a cooling chamber at constant temperature of $4{ }^{\circ} \mathrm{C}$ under continuous stirring. The decreasing temperature of the solution was monitored using an EasyLog USB (Lascar electronics, UK). Samples were taken every approximately $30 \mathrm{~min}$ for the analysis of the succinic acid concentration in the solution. 


\subsection{Succinic acid recovery process}

Four succinic acid rich media, either synthetic solutions or actual fermentation broths (Table 1), were used for the evaluation of succinic acid separation and purification using the five DSP (Figure 1). The first medium used was a synthetic solution (medium 1) containing pure-commercial compounds that was prepared based on the fermentation results achieved by B. succiniciproducens when it was cultivated on pretreated SSL via liquid-liquid extraction for removal of phenolic compounds coupled with nanofiltration as it was reported by Alexandri et al. [5]. The second medium used was a simulated fermentation broth (medium 2) with the same composition of succinic, lactic, acetic and formic acids as in the case of medium 1 containing also $10 \mathrm{~g} / \mathrm{L}$ of $\mathrm{LS}$ as in the case of actual fermentation broths produced by B. succiniciproducens cultivation on pretreated SSL as reported by Alexandri et al. [5]. The third medium used was an actual fermentation broth obtained from an A. succinogenes fermentation (medium 3) carried out using a synthetic medium containing mixed sugars at the same proportion as the one contained in SSL, as reported by Pateraki et al. [6]. The fourth medium was obtained from a B. succiniciproducens fermentation using pretreated SSL via nanofiltration, according to the methodology described by Alexandri et al. [5], as fermentation feedstock supplemented with yeast extract and various salts as sources of minerals (medium 4). For every test of DSP (besides reactive extraction), $100 \mathrm{~mL}$ of each solution was used in order to evaluate the recovery efficiency of succinic acid.

\subsubsection{Calcium precipitation method}

The calcium precipitation method used was based on the study of Luque et al. [9]. Specifically, $100 \mathrm{~mL}$ of fermentation broth (media 3 and 4) were centrifuged (15 min, 9,000 $\mathrm{rpm}, 4{ }^{\circ} \mathrm{C}$ ) in order to remove the bacterial cells. The supernatant was then filtered through 
Whatman No. 1 paper. The filtrate was mixed with 3\% (w/v) activated carbon (medium 3) or $12.5 \%(\mathrm{w} / \mathrm{v})$ (medium 4$)$ for $1 \mathrm{~h}$ in order to decolorise the sample. The suspension was then filtered and the $\mathrm{pH}$ of the clear broth was adjusted to around 13.5 by adding approximately $20 \%(\mathrm{w} / \mathrm{v})$ calcium hydroxide solution and the mixture was placed on a shaker at $200 \mathrm{rpm}$ and $39{ }^{\circ} \mathrm{C}$ for $20 \mathrm{~h}$. Precipitated calcium succinate was filtered off and washed with water. Distilled water was used and an excess of $\mathrm{H}_{2} \mathrm{SO}_{4}$ was added to form calcium sulfate. When the $\mathrm{pH}$ reached a value of around 2.5 , the calcium sulfate precipitate was removed via filtration. The precipitate was washed twice with $40 \mathrm{~mL}$ distilled water in order to remove the remaining succinic acid. Vacuum evaporation was then carried out in order to remove the residual volatile carboxylic acids. The final solution was concentrated to $20 \%$ of its original volume and the crystallisation of succinic acid was carried out at $4{ }^{\circ} \mathrm{C}$ for $24 \mathrm{~h}$. The crystals were filtered and washed with a cold saturated synthetic succinic acid solution and then dried for $12 \mathrm{~h}$ at $70{ }^{\circ} \mathrm{C}$. Final yield and purity were calculated according to the following equations:

Recovery yield $(\%)=\frac{\text { Dry weight of recovered succinic acid }(g)}{\text { Dryweight of succinic acid in the initial liquid medium }(g)} \quad$ Eq.1

Purity $(\%)=\frac{\text { Dry weight of the recovered succinic acid }(g)}{\text { Total dry weight of the recovered sample }(g)}$

Eq. 2

\subsubsection{Direct crystallisation method}

The direct crystallisation method was applied in two synthetic media (media 1 and 2) and two actual fermentation broths (media 3 and 4). Fermentation broths (100 mL) were centrifuged (15 min, 9,000 rpm, $4{ }^{\circ} \mathrm{C}$ ) to separate the bacterial cells. The supernatant was filtered through Whatman No.1 paper. Activated carbon was mixed with the filtrate for $1 \mathrm{~h}$ to decolorise the broth. The concentration of the activated carbon varied depending on the fermentation medium used. The suspension was then filtered and the clear fermentation broth 
was treated either via acidification with $\mathrm{H}_{2} \mathrm{SO}_{4}$ or with cation-exchange resins. The resulting solution was vacuum evaporated at $60{ }^{\circ} \mathrm{C}$ to remove the volatile carboxylic acids, such as acetic acid and formic acid.

When synthetic media were used, the steps involving centrifugation, treatment with activated carbon and filtration were omitted. Acidification of the solutions was not required since the $\mathrm{pH}$ value was around 2. Vacuum evaporation was directly employed, which was carried out in the same way as in the case of actual fermentation broths.

The evaporation was terminated when each solution was concentrated to approximately $20 \%$ of its original volume. Subsequently, crystallisation of succinic acid was carried out at $4{ }^{\circ} \mathrm{C}$ for $24 \mathrm{~h}$ in all cases. The final slurry was filtered through Whatman No.1 paper and the crystals were carefully washed with a saturated synthetic solution of succinic acid to remove impurities. The succinic acid crystals were dried at $70{ }^{\circ} \mathrm{C}$ for $12 \mathrm{~h}$.

\subsubsection{Direct crystallisation method with acidification}

This method was tested on the two actual fermentation broths (media 3 and 4). The $\mathrm{pH}$ of the actual fermentation broth was adjusted to 2.0 using $98 \%$ sulfuric acid. Vacuum evaporation and crystallisation were then carried out as previously reported.

\subsubsection{Direct crystallisation using a cation-exchange resin.}

The conversion of the sodium and magnesium salts into acids was carried out using a cationic resin of sulfonic $\left(\mathrm{SO}_{3} \mathrm{H}\right)$ type, Amberlite IR $120 \mathrm{H}$, based on a polystyrenedivinylbenzene copolymer, according to the process developed by Lin et al. [17]. The fermentation broth $(100 \mathrm{~mL})$ was passed through $50 \mathrm{~g}$ of resin. The $\mathrm{pH}$ of the effluent was 2.0. The acidified medium was then vacuum evaporated, crystallised and dried as described in section 2.3.2. This method was employed on media 3 and 4. 
When re-crystallisation was carried out in the case of medium 4, the crystals obtained after washing were dissolved in ultrapure water. The volume of the solution was the same as the one obtained by vacuum evaporation. Using heating and stirring they were fully dissolved and then subjected to crystallisation. Washing and drying was carried out as previously described. Re-crystallisation was carried out only in the case that cation-exchange resins were used. The obtained recovery yield and purity of the succinic acid crystals were determined according to equations (1) and (2).

\subsubsection{Salting-out}

Salting-out extraction was carried out according to the methodology presented by Sun et al. [18] on an actual fermentation broth produced by A. succinogenes (medium 3). The fermentation broth $(100 \mathrm{~mL})$ was treated with $76 \%$ (v/v) $\mathrm{H}_{2} \mathrm{SO}_{4}$ until the $\mathrm{pH}$ reached a value of 3. Then, $30 \%(\mathrm{v} / \mathrm{v})$ acetone and $20 \%(\mathrm{w} / \mathrm{v})\left(\mathrm{NH}_{4}\right)_{2} \mathrm{SO}_{4}$ were added and the mixture was shaken. The mixture was allowed to settle for $8 \mathrm{~h}$ in order to allow phase separation. Succinic acid was extracted in the acetone phase. Activated carbon was added to the succinic acidacetone phase in order to remove the residual organic impurities. The next step involved filtration in order to remove the activated carbon and the filtrate was vacuum evaporated to recover acetone and to concentrate the succinic acid solution. Subsequently, crystallisation was carried out at a pH value of 2.0 at $4{ }^{\circ} \mathrm{C}$ for $24 \mathrm{~h}$. Finally, succinic acid crystals were washed as previously stated and dried at $70{ }^{\circ} \mathrm{C}$ for $10 \mathrm{~h}$. Yield and purity were calculated according to equations (1) and (2).

\subsubsection{Reactive extraction}

The list of amines and solvents used for reactive extraction are shown in Table 2 together with some of their main properties. The selection of the chemicals was carried out 
based on the study of Kurzrock and Weuster-Botz [14]. The amine concentration used in all cases was $0.5 \mathrm{~mol} / \mathrm{kg}$ solvent. When medium 1 was used, no $\mathrm{pH}$ adjustment was carried out. When medium 4 was employed, centrifugation, treatment with activated carbon were initially employed and $\mathrm{pH}$ adjustment was carried out using either cation-exchange resins or $10 \mathrm{M}$ $\mathrm{NaOH}$. Then, $500 \mu \mathrm{L}$ of succinic acid solution (using medium 1 or medium 4) were mixed with $500 \mu \mathrm{L}$ of a selected reactive extraction system. The two phases were mixed vigorously for $5 \mathrm{~min}$. Subsequently, the mixture was centrifuged ( $5 \mathrm{~min}, 4,500 \mathrm{rpm}$ ) and the aqueous phase was used for analysis of the remaining organic acids, whereas the organic phase was kept for further processing.

Back-extraction of succinic acid was carried out by either $\mathrm{pH}$-swing or temperatureswing using the organic phases from the extraction systems trioctylamine in 1-hexanol and dioctylamine in 1-octanol used during reactive extraction of succinic acid from medium 4 . In the case of $\mathrm{pH}$-swing, $1 \mathrm{~mL}$ of the organic phases, produced by both extraction systems during reactive extraction, was vigorously mixed with $6 \mathrm{~mL}$ aqueous solution of $\mathrm{NaOH}(\mathrm{pH}$ 13) for $12 \mathrm{~h}$. Then, the two phases were separated via centrifugation and the aqueous phase was analysed for organic acids. Three different methodologies of temperature-swing were applied using the organic phases from the extraction systems trioctylamine in 1-hexanol and dioctylamine in 1-octanol applied during reactive extraction. Each organic phase $(1 \mathrm{~mL})$ was mixed with $6 \mathrm{~mL}$ of distilled water. The organic phase from the extraction system trioctylamine in 1-hexanol was back-extracted either in an ultrasonic bath for $9 \mathrm{~h}$ or in a water bath for $9 \mathrm{~h}$ at $50{ }^{\circ} \mathrm{C}$ [24]. In all cases, phase separation was achieved via centrifugation and the aqueous phase was analysed for organic acids.

The most efficient process combining reactive extraction and back-extraction was then carried out in $50 \mathrm{~mL}$ of medium 4 and the aqueous phase was concentrated using vacuum evaporation in order to increase the final succinic acid concentration. Crystallisation, washing, 
and drying of the crystals were also carried out as previously described and crystal yield and purity were calculated using equations (1) and (2).

\subsection{Analytical Methods}

\subsubsection{Determination of sugars, organic acids and LS}

Determination of sugars and organic acids was performed by an HPLC SHIMADZU UFLC XR system (isocratic pump, autosampler, RI Detector and column oven) equipped with a Biorad Aminex HPX-87H column with size $300 \mathrm{~mm}$ x $7.8 \mathrm{~mm}$ or a Phenomenex Rezex ROA Organic acids $\mathrm{H}+$ with the same size. The mobile phase in both columns was $10 \mathrm{mM}$ $\mathrm{H}_{2} \mathrm{SO}_{4}$ aqueous solution with $0.6 \mathrm{~mL} / \mathrm{min}$ flow rate and the column temperature was $45^{\circ} \mathrm{C}$ for the Biorad column and $70{ }^{\circ} \mathrm{C}$ when the Phenomenex column was used.

LS determination was carried out according to the UNE EN 16109:2012 protocol as described by Alexandri et al. [5].

\subsubsection{NMR analysis}

The succinic acid crystals obtained by the most efficient DSP were analysed for impurities using NMR. NMR spectra were carried out on a Brucker Ultrafield 400 Plus spectrophotometer in $\mathrm{CD}_{3} \mathrm{OD}$, operating at $400 \mathrm{MHz}$. Maleic acid was used as internal standard. Singlet was set at $6.32 \mathrm{ppm}, 2 \mathrm{H}$.

\subsubsection{GC-MS Analysis}

GC-MS analyses were performed using Perkin Elmer Clarus 680 GC with 600 GC-MS equipped with an autosampler. Injections were performed with a split ratio of $10: 1$ at $250{ }^{\circ} \mathrm{C}$ and the injection volume was $1 \mu \mathrm{L}$. The separation was carried out on a DB-5MS column (30m, $0.25 \mathrm{~mm}$ ID, $0.25 \mu \mathrm{m}$ film thickness). Helium flow rate was set at $1 \mathrm{~mL} / \mathrm{min}$. The 
temperature program was the following: start at $35{ }^{\circ} \mathrm{C}$, hold for $5 \mathrm{~min}$; ramp rate- $10{ }^{\circ} \mathrm{C} / \mathrm{min}$ to $300{ }^{\circ} \mathrm{C}$; hold for $5 \mathrm{~min}$. The MS in TIC were acquired in the range of $\mathrm{m} / \mathrm{z}$ of $35-1000$ at a scan rate of 2.5 scans/s using EI of $70 \mathrm{eV}$ [25]. Succinic acid samples (0.5 mg) were suspended in MeCN $(100 \mu \mathrm{L})$ and BSTFA (+ 0.1\% TMCS, $50 \mu \mathrm{L})$ was added. In addition, the solution became clear and was allowed to stand at room temperature for 15 min to ensure a complete derivatisation. The standard was added $(500 \mu \mathrm{L}$ at $1 \mathrm{mg} / \mathrm{mL}$ in $\mathrm{MeCN})$ and a total volume was made up to $1 \mathrm{~mL}$ using MeCN. The sample was then analysed using GC-MS. $O$ terphenyl was used as internal standard. Retention time was 24.46 min and $\mathrm{m} / \mathrm{z}=230$.

\section{Results \& Discussion}

\subsection{Treatment with activated carbon}

The use of activated carbon is necessary for every DSP using simulated or actual fermentation broths for the removal of impurities (e.g. proteins, pigments, LS) that contribute to the dark coloration of the broth. Depending on the origin of the solution used to evaluate the different DSP, varying quantities of activated carbon were required. In pure-commercial organic acid solutions (medium 1), the use of activated carbon was not necessary. When medium 3 (actual fermentation broth obtained via $A$. succinogenes cultivation in synthetic medium) was used, $3 \%(\mathrm{w} / \mathrm{v})$ of activated carbon was sufficient for complete decoloration of the broth. However, in real SSL-based fermentation broths produced by B. succiniciproducens (medium 4) higher quantities of activated carbon were required for effective color removal. Five different quantities of activated carbon $(0 \%, 3 \%, 7.5 \%, 12.5 \%$ and $20 \%$, w/v) were tested in medium 4 in order to evaluate the efficiency of color removal with respect to the added amount of activated carbon. The color removal was evaluated by measuring the optical density at $400 \mathrm{~nm}$ of the five solutions (Figure 2). It is obvious that in order to achieve almost complete color removal in medium 4, around $12.5 \%$ (w/v) of activated carbon should be 
applied. It is worth noting that fermentation broths containing LS concentrations higher than $100 \mathrm{~g} / \mathrm{L}$ were not discolorised even with high quantities of activated carbon.

Activated carbon adsorbs succinic acid and the succinic acid losses depend on the amount of activated carbon used for color removal. Hydration of activated carbon with water or even better with fermentation broth should be applied in order to avoid succinic acid losses during decolorisation of the broths with activated carbon.

\subsection{Effect of crystallisation duration}

The crystallisation step is necessary in order to achieve succinic acid crystals of high purity. In the chemical industries, batch crystallisation is a commonly used unit operation. The crystallisation process should be optimised in order to obtain the appropriate crystal size distribution as well as a good repeatability from batch to batch operation [26]. The cooling rate is very important as it affects directly not only supersaturation but also the crystal size distribution. In industrial applications, there is a lack of kinetic data regarding crystallisation profile. Aiming to optimise this process, the crystallisation rate of succinic acid was monitored by calculating the diluted succinic acid in a synthetic solution containing approximately $190 \mathrm{~g} / \mathrm{L}$ of succinic acid at $80{ }^{\circ} \mathrm{C}$. Crystallisation was carried out under continuous stirring. Within $1.5 \mathrm{~h}$ of crystallisation, the soluble succinic acid reached a concentration of around $36 \mathrm{~g} / \mathrm{L}$ at $4{ }^{\circ} \mathrm{C}$ which is close to its theoretical $(30 \mathrm{~g} / \mathrm{L})$ solubility at 4 ${ }^{\circ} \mathrm{C}$. This experiment showed that when the target temperature was reached, crystallisation of succinic acid reached a plateau. The crystallisation is affected by agitation as it influences both mass transfer and crystal formation [26] and by the impurities that are present in the solution. Feng and Berglund [26] studied the effect of the addition of acetic acid in the cooling profile showing that the presence of $2 \mathrm{~mol} \%$ of acetic acid leads to reduced crystal 
growth rate. For this reason, vacuum evaporation prior to crystallisation is very important as it removes the volatile acetic and formic acids leading to succinic acid recovery of high purity.

\subsection{Calcium precipitation method}

The use of the calcium precipitation method is traditionally applied in the industry mainly for the recovery of citric acid and lactic acid [2]. The recovery of succinic acid using calcium hydroxide in laboratory scale were described by Berglund et al. [27] and Datta et al. [28]. Datta et al. [28] reported a final purity of succinic acid of $94.2 \%$. This method is generally considered quite effective for the removal of residual sugars, proteins, and other impurities. However, this process is very slow and requires high energy consumption [9]. In this study, it was mainly evaluated for comparison reasons.

The calcium precipitation method was applied in two different fermentation broths, one derived from a fermentation using $A$. succinogenes cultivated in a synthetic medium (medium 3) and the other using B. succiniciproducens cultivated in SSL-based medium (medium 4). Both samples were treated in the same way with the exception of the activated carbon step. In the case of medium 3, 3\% (w/v) of activated carbon was used, whilst in the case of medium 4, 12.5\% (w/v) of activated carbon was necessary in order to achieve complete color removal. After evaporation and crystallisation, the succinic acid yield was $8.1 \%$ in the case of medium 3 and $13.1 \%$ in the case of medium 4 , while the purities achieved were $87.2 \%$ and $81 \%$, respectively. HPLC analysis showed that the main impurities present in the succinic acid crystals derived from medium 3 were formic and acetic acids, as per $1 \mathrm{~g}$ of total crystals recovered approximately $0.003 \mathrm{~g}$ of each by-product was detected. In the succinic acid crystals derived from medium 4, formic and acetic acids were not detected, but $0.17 \mathrm{~g}$ of lactic acid was detected per $1 \mathrm{~g}$ of total crystals. 
Luque et al. [9] reported a succinic acid recovery yield of $13 \%$ and a crystal purity of $30 \%$ when the calcium precipitation method was applied for the recovery of succinic acid from a semi-defined medium containing $35.3 \mathrm{~g} / \mathrm{L}$ succinic acid, $8.1 \mathrm{~g} / \mathrm{L}$ acetic acid, $6.3 \mathrm{~g} / \mathrm{L}$ formic acid and $1 \mathrm{~g} / \mathrm{L}$ of pyruvic acid. Datta et al. [28] reported a succinic acid purity of $89.6 \%$ when the calcium precipitation method was applied in a fermentation broth derived from Anaerobiospirillum succiniciproducens culture on dextrose-based defined medium.

\subsection{Salting-out}

Salting-out extraction is a separation method that is applied in order to extract a hydrophilic molecule from an aqueous solution by using an organic solvent as the extractant and a salt as the salting-out reagent. The advantages of this technique include the low-cost, the low interfacial tension, the good resolution, the high yield and capacity and the simplicity of scaling up the system [29]. Furthermore, bacterial cells and proteins are simultaneously removed from the fermentation broth, avoiding centrifugation and/or filtration steps. The overall succinic acid recovery yields were higher than $60 \%$ and the purities were higher than $91 \%$ when salting out was applied in synthetic fermentation media as a separation method for the recovery of succinic acid $[18,30,31]$.

Salting-out extraction was applied in media 3 and 4 (Table 1), following the method of Sun et al. [18]. The $\mathrm{pH}$ of the fermentation broths was initially adjusted to 3 and then acetone (the extractant) and $\left(\mathrm{NH}_{4}\right)_{2} \mathrm{SO}_{4}$ (the salting-out reagent) were added to the fermentation broths. In this process, biomass removal and activated carbon treatment were not employed as primary separation steps. After $8 \mathrm{~h}$, three distinct phases were observed: a) the upper phase contained the organic solvent (acetone) that is rich in succinic acid, b) the middle phase that contained the biomass, and c) the lower aqueous phase containing residual sugars, proteins and other impurities. Phase separation was carried out via decanting. The succinic acid rich 
phase was subsequently treated with appropriate concentrations of activated carbon, (i.e. $3 \%$ in the case of medium 3 and $12.5 \%$ in the case of medium 4). After color removal, acetone was recovered via vacuum evaporation. The succinic acid recovery yield was $50 \%$ in both cases. The purity of the succinic acid crystals from media 3 and 4 was $94 \%$ and $86 \%$, respectively. The succinic acid crystals contained a significant quantity of xylose, which accounted for approximately $0.05 \mathrm{~g}$ xylose per g succinic acid crystals when medium 3 was used and $0.1 \mathrm{~g}$ xylose per $\mathrm{g}$ succinic acid crystals when medium 4 was used. The higher xylose content in the case of medium 4 could be attributed to the higher initial xylose concentration in this medium. Sun et al. [18] reported that salting-out coupled with crystallisation led to succinic acid recovery yield of $65 \%$ with a purity of $91 \%$ using a glucose-based defined fermentation medium and a bacterial strain isolated from sea mud.

It should be stressed that actual fermentation broths produced in industrial optimized fermentation processes will not contain any xylose leading to higher purities. However, the achieved yield is considered low to ensure cost-competitiveness.

\subsection{Direct crystallisation method}

The direct crystallisation method was initially reported by Luque et al. [9]. Bacterial fermentations are carried out at a $\mathrm{pH}$ range of 6-7, above the $p K_{a}$ value of succinic acid rendering acidification of the broth necessary in order to efficiently separate the succinic acid crystals via crystallisation. The $\mathrm{pH}$ of the solution should be 2.0 as in this value succinic acid exists in its undissociated form and can be crystallised in higher yields than mono- or disuccinate [17]. After acidification, vacuum evaporation is applied to remove the volatile organic acids, acetic and formic acids, and increase approximately five times the succinic acid concentration. The direct crystallisation method using $\mathrm{H}_{2} \mathrm{SO}_{4}$ or cation exchange resins was applied in media 1-4 (Table 1). 
Figure 3 presents the recovery yield and the purity of the succinic acid crystals obtained by the direct crystallisation methods using both $\mathrm{H}_{2} \mathrm{SO}_{4}$ and cation exchange resins. In the case of pure organic acid solution (medium 1), the steps involving the addition of activated carbon and acidification were omitted, and subsequent treatment with evaporation and crystallisation led to $72.5 \%$ succinic acid recovery yield with $87.1 \%$ crystal purity (Figure 3A). The simulated fermentation broth (medium 2) was treated with activated carbon but not with resins or $\mathrm{H}_{2} \mathrm{SO}_{4}$ as the $\mathrm{pH}$ of the broth was already around 2. The succinic acid recovery yield $(60 \%)$ achieved was lower than the pure organic acid solution, but the crystal purity (89.8\%) was higher (Figure 3B).

Both direct crystallisation methods were applied in medium 3. Acidification with $\mathrm{H}_{2} \mathrm{SO}_{4}$ resulted in a succinic acid recovery yield of $53 \%$ and succinic acid crystal purity of 88\% (Figure 3C). Higher succinic acid yield (74.6\%) and purity (99.3\%) were achieved with the use of cation-exchange resins (Figure 3D). When medium 4 was used, the treatment with cation exchange resins led to enhanced recovery yield (79\%) and purity (96\%) of the separated succinic acid crystals (Figure $3 \mathrm{~F}$ ), than acidification with $\mathrm{H}_{2} \mathrm{SO}_{4}$ that led to lower recovery yield (57\%) and purity (90\%) (Figure 3E). The lower purity of the crystals in the case of acidification can be attributed to the formation of salts that could not be detected via HPLC. Lin et al. [17] also reported the formation of potassium sulphate salts that can significantly affect the final succinic acid crystal purity.

Li et al. [32] employed crystallisation as the first recovery step, at $\mathrm{pH}$ value lower than 2 and $4{ }^{\circ} \mathrm{C}$, in the separation of succinic acid from a fermentation broth derived by glucosebased cultures of $A$. succinogenes leading to succinic acid recovery yield of $70 \%$ and purity of 90\%. Lin et al. [17] reported that the application of the direct crystallisation method using cation-exchange resins in a real fermentation broth produced by the bacterial strain $A$. succinogenes led to succinic acid recovery yield and purity of $89.5 \%$ and $99 \%$, respectively. 
The fermentation medium used by Lin et al. [17] was wheat-derived hydrolysate with glucose as carbon source. The lower succinic acid recovery yield obtained in this study could be attributed to the complexity of the SSL used as fermentation feedstock for the production of succinic acid.

In the succinic acid crystals recovered from direct crystallisation after treatment with cation-exchange resins using medium 4, a re-crystallisation step was also carried out in order to enhance the purity of the sample. Succinic acid crystal purity was increased to approximately $99 \%$.

\subsection{Reactive extraction}

Reactive extraction, using high molecular weight amines is a well-known method for the extraction of organic acids [14]. The term "reactive" is used in order to differentiate these reactions from the conventional extraction mechanisms. In reactive extraction, the carboxylic acid and the extractant form a complex or a new compound due to intermolecular or chemical-based interactions $[10,33]$. In the case of succinic acid downstream separation, longchain aliphatic primary, secondary and tertiary amines have been proposed for its reactive extraction from aqueous solutions [34-36]. Primary amines show high solubility in the aqueous phase. Secondary amines present the highest distribution coefficients but tend to form amides during regeneration by distillation. Primary, secondary and tertiary amines can only extract the undissociated form of the acid. On the other hand, quaternary ammonium salts can extract both dissociated and undissociated forms of the acid, but their regeneration by back-extraction is not easily accomplished [14]. Consequently, tertiary amines are the most promising extractants for reactive extraction of carboxylic acids [24].

The $p K_{a}$ of the organic acid as well as the $\mathrm{pH}$ of the aqueous solution play an important role in reactive extraction. When tertiary amines are used, the $\mathrm{pH}$ of the aqueous 
solution must be under the $p K_{a}$ of the organic acid, because at $\mathrm{pH}$ values above $p K_{a}$ the dissociated form of the acid is increased, leading to low extraction yields. Furthermore, in case of dicarboxylic acids, the distribution coefficient $\left(k_{d}\right)$ decreases significantly at $\mathrm{pH}$ values between $p K_{a 1}$ and $p K_{a 2}[13]$.

The selection of the reactive extraction systems used in this study was based on a thorough literature review on reactive extraction systems for the recovery of succinic acid [14]. Secondary and tertiary amines and one primary amine in various solvents were selected for succinic acid separation from fermentation broths. Initially, five amines, four dissolved in 1-octanol and one in 2-octanol, were tested in medium 1 (Figure 4). The extraction yields were higher than $90 \%$ in almost all the reactive extraction systems employed. The system trioctylamine in 1-octanol extracted almost $95 \%$ of succinic acid, whereas the lowest succinic acid recovery yield (90\%) was observed when trihexylamine in 2-octanol extraction system was used.

The efficiency of reactive extraction and the selectivity of the amines selected were then tested in a real fermentation broth derived via B. succiniciproducens cultivation in SSLbased media (medium 4). Tables 3 and 4 present the extraction yields achieved for each organic acid present in the fermentation broth by the different extraction systems used at $\mathrm{pH}$ values 2 and 5. At $\mathrm{pH}$ value of 2 , the vast majority (13 out of 15 ) of the reactive extraction systems were able to remove more than $90 \%$ of succinic acid from the fermentation broth, with dioctylamine in 1-octanol reaching a succinic acid extraction yield of $100 \%$. Furthermore, at a $\mathrm{pH}$ value of 2 , all organic acids, besides formic acid that reacted fairly or not at all, were co-extracted in high removal yields (Table 3). Besides, dioctylamine in 1octanol, also dioctylamine in 1-hexanol, trioctylamine in 1-hexanol and diisoctylamine in 1octanol resulted in the extraction of almost all organic acids and only residual sugars 
remained in the aqueous phase. In this way, the produced organic acids can be separated from the residual sugars.

At a $\mathrm{pH}$ value of 5, the extraction yield of succinic acid was much lower (Table 4) than the extraction achieved in a $\mathrm{pH}$ value of 2 . However, in many cases, the extraction yields of fermentation by-products were much higher than succinic acid, which remained in the aqueous phase. For instance, the extraction systems dihexylamine in 1-hexanol and tripentylamine in 1-butanol led to complete removal of formic acid, more than $56 \%$ removal of lactic acid and more than $42 \%$ removal of acetic acid, while the removal of succinic acid was lower than $14.2 \%$. It should be stressed that lactic acid removal from the aqueous phase is beneficial because this organic acid is less easily removed via vacuum evaporation and crystallisation. Especially in the case of the extraction system dihexylamine in 1-hexanol, the extraction yield of lactic acid was $67.1 \%$. Reactive extraction at $\mathrm{pH}$ value of 5 could be applied in the case of $B$. succiniciproducens due to the production of lactic acid by this strain.

Two back extraction techniques, namely temperature swing and $\mathrm{pH}$-swing, were evaluated in order to recover the succinic acid from the acid-amine complex and recycle the amine back to the extraction system. The latter method is based on the dependence of the undissociated acid to the $\mathrm{pH}$ value of the aqueous solution. A higher $\mathrm{pH}$ value than the $p K_{a}$ of succinic acid inhibits the formation of the amine-acid complex making possible to backextract the acid to the aqueous phase. An increased temperature is another way to break down the complex because the reactions in the interface of the aqueous and the organic phase involve proton transfer or hydrogen-bond formation and are expected to be exothermic.

The extraction systems that were selected to evaluate the two back extraction methods were trioctylamine in 1-hexanol and dioctylamine in 1-octanol that led to high succinic acid extraction yield at $\mathrm{pH}$ 2. In the case of $\mathrm{pH}$-swing using the organic phase obtained from both extraction systems during reactive extraction, the succinic acid recovery (100\%) achieved 
when the extraction system trioctylamine in 1-hexanol was used for reactive extraction was much higher than the succinic acid recovery achieved (65\%) when the organic phase from the extraction system dioctylamine in 1-octanol was used. As trioctylamine is a tertiary amine, the steric hindrance facilitates the back-extraction via $\mathrm{pH}$-swing, while the bonding between succinic acid and dioctylamine, which is a secondary amine, is stronger [35]. The disadvantage of the $\mathrm{pH}$-swing method is that the acid is recovered in a salt form and further acidification is required. Back extraction of succinic acid by temperature-swing was less efficient than $\mathrm{pH}$-swing, as less than $30 \%$ of succinic acid was recovered. In the case that the organic phase from the extraction system trioctylamine in 1-hexanol was used, the succinic acid recovery yields achieved were again higher than the ones obtained with the organic phase from the dioctylamine in 1-octanol extraction system. Furthermore, all fermentation byproducts were back-extracted in the aqueous phase. Nevertheless, the subsequent unit operations (i.e. evaporation and crystallisation) after reactive extraction and back extraction eliminate the residual by-products leading to purified succinic acid crystals.

The reactive extraction system trioctylamine in 1-hexanol followed by back-extraction with $\mathrm{pH}$-swing was the most efficient system. After back extraction, succinic acid is recovered in the form of sodium salts and subsequent treatment with cation-exchange resins, vacuum evaporation and crystallisation was applied. The total succinic acid recovery yield was $73 \%$ and crystal purity reached $97.2 \%$.

\subsection{Comparison of the different DSP}

Figure 1 presents the unit operations involved in each DSP evaluated in this study including the succinic acid recovery yield and purity achieved under the optimum conditions of the five DSP applied for the recovery of succinic acid from medium 4. Direct crystallisation using cation-exchange resins resulted in the highest succinic acid 
yield (79\%), whereas the highest purity was obtained via reactive extraction using backextraction with $\mathrm{pH}$-swing (97.2\%).

\subsection{Succinic acid crystal analysis by NMR and GC-MS}

GC-MS and NMR analyses were carried out in the succinic acid crystals obtained via direct crystallisation using cation exchange resins and reactive extraction using trioctylamine in 1-hexanol followed by back-extraction of succinic acid with pH-swing. GC-MS analysis of purified succinic acid crystals showed that they were free of formic, maleic, lactic and hydroxybutyric acids (Table 5). Palmitic acid was present in all samples, while linoleic acid was detected in the succinic acid crystals derived from process 2 (reactive extraction) and process 3 (direct crystallisation with cation-exchange resins followed by re-crystallisation). The presence of fatty acids is probably attributed to Eucalyptus globulus wood, the raw material used in the sulphite pulping process [37].

Low quantities of acetic acid are masked by derivatisation agents and their byproducts in MS total ion current chromatogram. Therefore, ${ }^{1} \mathrm{H}$ NMR analysis was employed for acetic acid quantification in the samples of succinic acid crystals. Furthermore, the final purity of succinic acid crystals was established by ${ }^{1} \mathrm{H}$ NMR analysis. Process 1 (direct crystallisation with cation-exchange resins) provided succinic acid crystals with purity of $c a$ $99 \%$ and acetic acid content of $0.24 \%(0.56 \mathrm{~mol} \%)$. The purity of succinic acid crystals was increased to higher than $99 \%$ when direct crystallisation with cation-exchange resins was combined with re-crystallisation (Process 3) resulting also to no acetic acid detection in this sample. Process 2 (reactive extraction with $\mathrm{pH}$ swing back extraction) provided succinic acid crystals with purity of $c a 98.5 \%$ and a acetic acid content of $0.14 \%$ (0.29 mol\%). These results indicate that it is feasible to produce succinic acid crystals with the required purity for further polymerisation into poly(butylene succinate). 


\section{Conclusions}

The development of an intergrated biorefinery in conventional sulphite pulp mills for the production of lignosulphonates, phenolics and succinic acid require also the development of an efficient DSP for the purification of succinic acid that will be suitable for poly(butylene succinate) production. This study showed that it is feasible to recover succinic acid crystals with purity higher than $99 \%$, low acetic acid content (less than 0.09 mol\% that is required for efficient polymerisation) and succinic acid recovery yield of $79 \%$. The techno-economic profitability of this process will be evaluated in a forthcoming study.

\section{Supplementary data}

The succinic acid losses observed when different quantities of activated carbon were used and the crystallisation profile of succinic acid as a function of time following a temperature ramp to $4{ }^{\circ} \mathrm{C}$ are provided as e-supplementary data and can be found in the e-version of this paper online.

\section{Acknowledgements}

The research leading to these results has received funding from the European Union's Seventh Framework Program (FP7) for research, technological development and demonstration under grant agreement $n^{\circ} 311935$. 


\section{References}

[1] C. Pateraki, M. Patsalou, A. Vlysidis, N. Kopsahelis, C. Webb, A.A. Koutinas, M. Koutinas, Actinobacillus succinogenes: Advances on succinic acid production and prospects for development of integrated biorefineries, Biochem. Eng. J. 112 (2016) 285-303.

[2] T. Kurzrock, D. Weuster-Botz, Recovery of succinic acid from fermentation broth, Biotechnol. Lett. 32 (2010) 331-339.

[3] E4tech, RE-CORD and WUR (2015) "From the sugar platform to biofuels and biochemicals". Final report for the European Commission, contract No. ENER/C2/4232012/SI2.673791

[4] M. Alexandri, H. Papapostolou, A. Vlysidis, C. Gardeli, M. Komaitis, S. Papanikolaou, A.A. Koutinas, Extraction of phenolic compounds and succinic acid production from spent sulphite liquor, J. Chem. Technol. Biotechnol. 91 (2016) 2751-2760.

[5] M. Alexandri, H. Papapostolou, M. Komaitis, L. Stragier, W. Verstraete, G.P. Danezis, C.A. Georgiou, S. Papanikolaou, A.A. Koutinas, Evaluation of an integrated biorefinery based on fractionation of spent sulphite liquor for the production of an antioxidant-rich extract, lignosulphonates and succinic acid, Bioresour. Technol. 214 (2016) 504-513.

[6] C. Pateraki, D. Ladakis, L. Stragier, W. Verstraete, I. Kookos, S. Papanikolaou, A. Koutinas, Pretreatment of spent sulphite liquor via ultrafiltration and nanofiltration for bio-based succinic acid production, J. Biotechnol. 233 (2016) 95-105.

[7] D. Ladakis, K. Michailidi, A. Vlysidis, A. Koutinas, I.K. Kookos, Valorization of spent sulphite liquor for succinic acid production via continuous fermentation system, Biochem. Eng. J. 137 (2018) 262-272. 
[8] D.L.A. Fernandes, S.R. Pereira, L.S. Serafim, D.V. Evtuguin, A.M.R.B. Xavier, Second generation bioethanol from lignocellulosics: Processing of hardwood sulphite spent liquor, In: M.A.P. Lima (Ed.), Bioethanol, InTech, Rijeka, 2012, pp. 123-152.

[9] R. Luque, C.S.K. Lin, C. Du, D.J. Macquarrie, A. Koutinas, R. Wang, C. Webb, J.H. Clark, Chemical transformations of succinic acid recovered from fermentation broths by a novel direct vacuum distillation-crystallisation method, Green Chem. 11(2009) 193200.

[10] C.S. López-Garzón, A.J.J. Straathof, Recovery of carboxylic acids produced by fermentation, Biotechnol. Adv. 32 (2014) 873-904.

[11] J. Xu, B.H. Guo, Poly(butylene succinate) and its copolymers: Research, development and industrialization, Biotechnol. J. 5 (2010) 1149-1163.

[12] J.G. Zeikus, M.K. Jain, P. Elankovan, Biotechnology of succinic acid production and markets for derived industrial products, Appl. Microbiol. Biotechnol. 51 (1999) 545552.

[13] Y.S. Huh, Y.S. Jun, Y.K. Hong, H. Song, S.Y. Lee, W.H. Hong, Effective purification of succinic acid from fermentation broth produced by Mannheimia succiniciproducens, Process Biochem. 41 (2006) 1461-1465.

[14] T. Kurzrock, D. Weuster-Botz, New reactive extraction systems for separation of biosuccinic acid, Bioprocess Biosyst. Eng. 34 (2011) 779-787.

[15] D. Caşcaval, L. Kloetzer, A.-I. Galaction, A. Vlysidis, C. Webb, Fractionation of carboxylic acids mixture obtained by succinic fermentation using reactive extraction, Sep. Sci. Technol. 48 (2013) 634-643.

[16] L. Fu, X. Gao, Y. Yang, F. Aiyong, H. Hao, C. Gao, Preparation of succinic acid using bipolar membrane electrodialysis, Sep. Purif. Technol. 127 (2014) 212-218. 
[17] S.K.C. Lin, C. Du, A.C. Blaga, M. Camarut, C. Webb, C.V. Stevens, W. Soetaert, Novel resin-based vacuum distillation-crystallisation method for recovery of succinic acid crystals from fermentation broths, Green Chem. 12 (2010) 666-671.

[18] Y. Sun, L. Yan, H. Fu, Z. Xiu, Salting-out extraction and crystallization of succinic acid from fermentation broths, Process Biochem. 49 (2014) 506-511.

[19] A. Orjuela, A. Orjuela, C.T. Lira, D.J. Miller, A novel process for recovery of fermentation-derived succinic acid: Process design and economic analysis, Bioresour. Technol. 139 (2013) 235-241.

[20] A. Orjuela, A.J. Yanez, L. Peereboom, C.T. Lira, D.J. Miller, A novel process for recovery of fermentation-derived succinic acid, Sep. Purif. Technol. 83 (2011) 31-37.

[21] Q. Li, D. Wang, G. Hu, J. Xing, Z. Su, Integrated bioprocess for high-efficiency production of succinic acid in an expanded-bed adsorption system, Biochem. Eng. J. 56 (2011) 150-157.

[22] Q. Yu, Z. Cui, Y. Zheng, H. Huo, L. Meng, J. Xu, C. Gao, Exploring succinic acid production by engineered Yarrowia lipolytica strains using glucose at low $\mathrm{pH}$, Biochem. Eng. J. in press, doi: 10.1016/j.bej.2018.08.001

[23] C. Pateraki, H. Almqvist, D. Ladakis, G. Lidén, A. A. Koutinas, A. Vlysidis, Modelling succinic acid fermentation using a xylose based substrate, Biochem. Eng. J. 114 (2016) $26-41$.

[24] E.Z. Lee, Y.S. Huh, Y.S. Jun, H.J. Won, Y.K. Hong, W.H. Hong, Effect of operating variables on back-extraction characteristics of succinic acid from organic phase, Biotechnol. Bioproc. Eng. 13 (2008) 342-346.

[25] J. Rousová, K. Ondrušová, P. Karlová, A. Kubátová, Determination of impurities in bioproduced succinic acid, J. Chromatogr. Sep. Tech. (2015) 6: 264. 
[26] L. Feng, K.A. Berglund, ATR-FTIR for determining optimal cooling curves for batch crystallization of succinic acid, Cryst. Growth Des. 2 (2002) 449-452.

[27] K.A. Berglund, P. Elankovan, D.A. Glassner, Carboxylic acid purification and crystallization process, 1991, USA Patent Number 5,034,105.

[28] R. Datta, D.A. Glassner, M.K. Jain, J.R.V. Roy, Fermentation and purification process for succinic acid, 1992, USA Patent Number 5,168,055.

[29] Z. Li, B. Jiang, D. Zhang, Z. Xiu, Aqueous two-phase extraction of 1,3-propanediol from glycerol-based fermentation broths, Sep. Purif. Technol. 66 (2009) 472-478.

[30] X. Li, Z. Zheng, Z. Wei, S. Jiang, L. Pan, S. Weng, Screening, breeding and metabolic modulating of a strain producing succinic acid with corn straw hydrolysate, World J. Microbiol. Biotechnol. 25 (2009) 667-677.

[31] J. Li, X.Y. Zheng, X.J. Fang, S.W. Liu, K.Q. Chen, M. Jiang, P. Wei, P.K. Ouyang, A complete industrial system for economical succinic acid production by Actinobacillus succinogenes, Bioresour. Technol. 102 (2011) 6147-6152.

[32] Q. Li, D. Wang, Y. Wu, W. Li, Y. Zhang, J. Xing, Z. Su, One step recovery of succinic acid from fermentation broths by crystallization, Sep. Purif. Technol. 72 (2010) 294300.

[33] K.K. Cheng, X.B. Zhao, J. Zeng, R.C. Wu, Y.Z. Xu, D.H. Liu, J.A. Zhang, Downstream processing of biotechnological produced succinic acid, Appl. Microbiol. Biotechnol. 95 (2012) 841-850.

[34] S.H. Hong, S.Y. Lee, Importance of redox balance on the production of succinic acid by metabolically engineered Escherichia coli, Appl. Microbiol. Biotechnol. 58 (2002) 286290. 
[35] Y.K. Hong, W.H. Hong, Removal of acetic acid from aqueous solutions containing succinic acid and acetic acid by tri-n-octylamine, Sep. Purif. Technol. 42 (2005) 151157.

[36] H. Song, Y.S. Huh, S.Y. Lee, W.H. Hong, Y.K. Hong, Recovery of succinic acid produced by fermentation of a metabolically engineered Mannheimia succiniciproducens strain, J. Biotechnol. 132 (2007) 445-452.

[37] A.P. Marques, D.V. Evtuguin, S. Magina, F.M.L. Amado, A. Prates, Chemical composition of spent liquors from acidic magnesium-based sulphite pulping of Eucalyptus globulus, J. Wood Chem. Technol. 29 (2009) 322-336. 


\section{Figure Captions}

Figure 1: Schematic diagram of the five DSP evaluated in this study including the final recovery yields and purities of succinic acid recovered from medium 4 utilising each different DSP (higher than 99\% purity was achieved when re-crystallisation was applied in the case of direct crystallization carried out with cation-exchange resins)

Figure 2: Color removal from medium 4 using various concentrations of activated carbon

Figure 3: Succinic acid recovery yield (black bars) and purity (grey bars) obtained using the direct crystallisation method. (A) medium 1; (B) medium 2; (C) medium 3 treated via acidification; (D) medium 3 treated via cation exchange resins; (E) medium 4 treated via acidification and $(\mathrm{F})$ medium 4 treated via cation exchange resins

Figure 4: Extraction yield of succinic acid from medium 1 (pure commercial organic acid solutions) using 5 reactive extraction systems

Figure 5: Succinic acid recovery via back extraction using temperature and $\mathrm{pH}$-swing. The black bars correspond to the reactive extraction system using trioctylamine in 1hexanol and the grey bars correspond to the reactive extraction system using dioctylamine in 1-octanol. (A) temperature swing using treatment in an ultrasonic bath for $9 \mathrm{~h}$; (B) temperature swing using treatment in a water bath for $5 \mathrm{~h}$ at $90{ }^{\circ} \mathrm{C}$;

(C) temperature swing using treatment in a water bath for $9 \mathrm{~h}$ at $50{ }^{\circ} \mathrm{C}$; (D) $\mathrm{pH}$ swing 
Figure 1

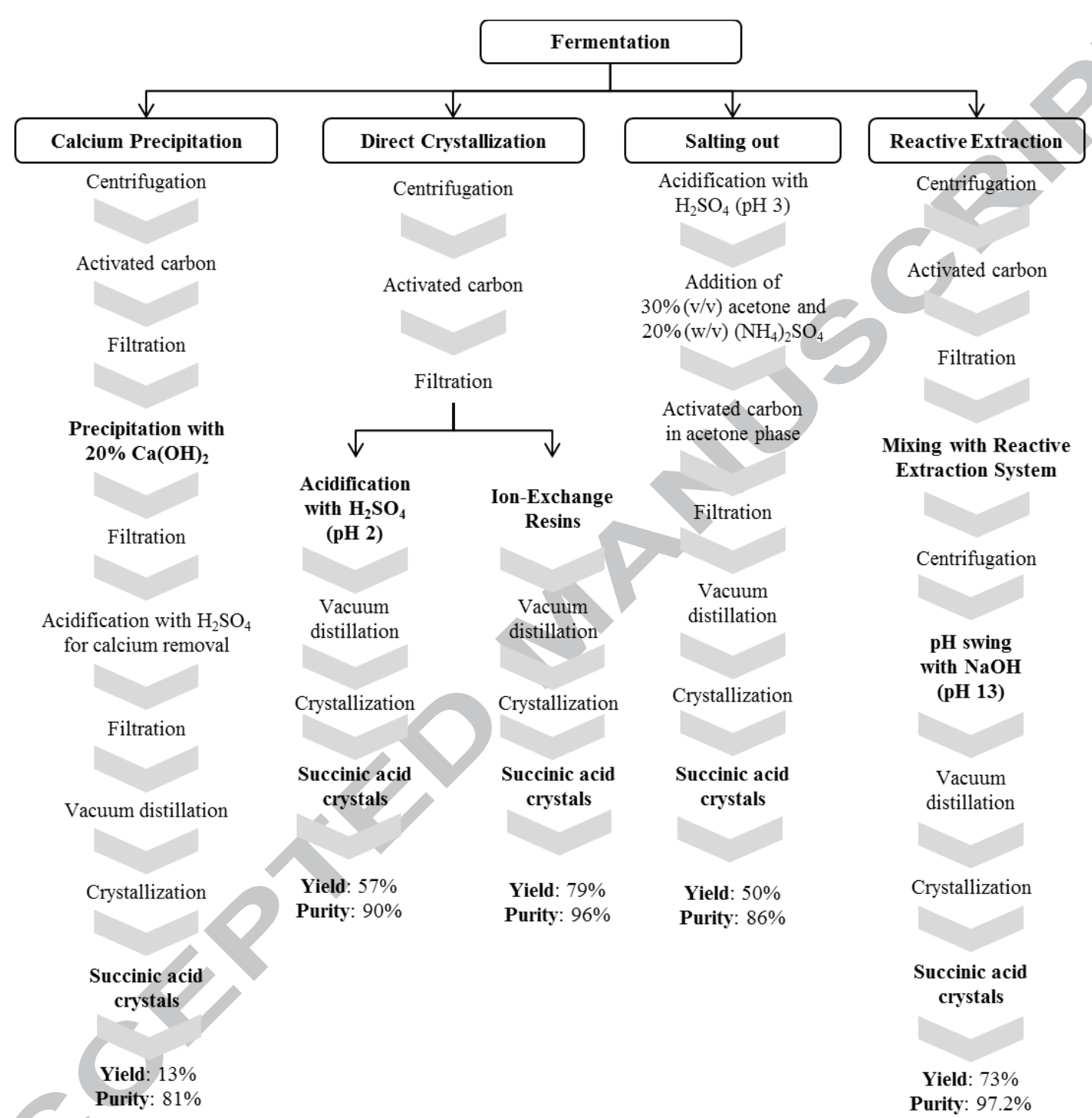


Figure 2

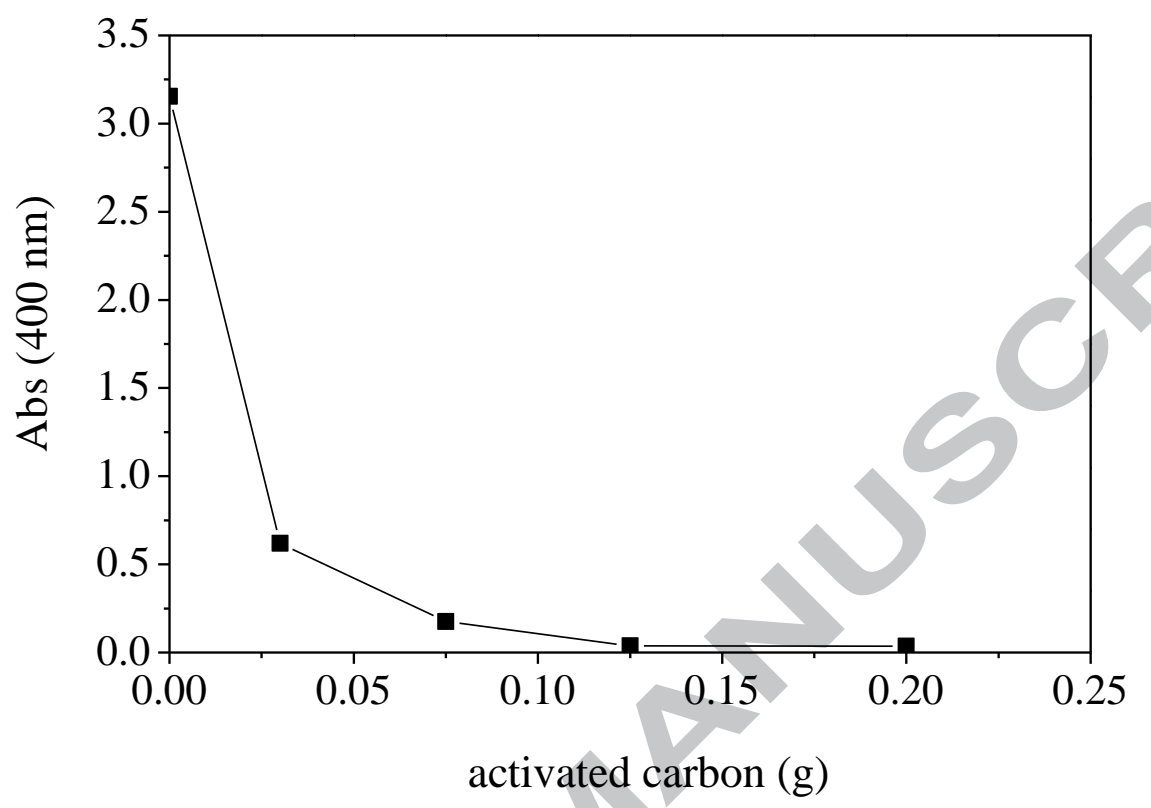


Figure 3



(A)

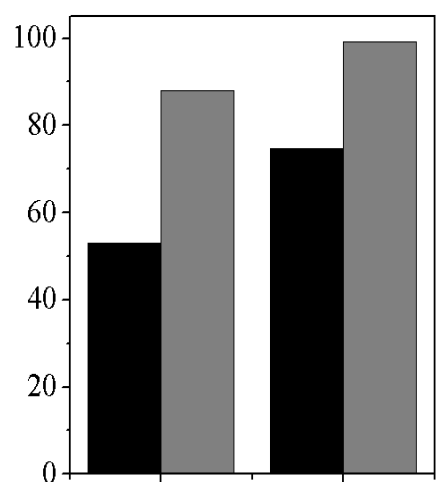

(C)

(D)

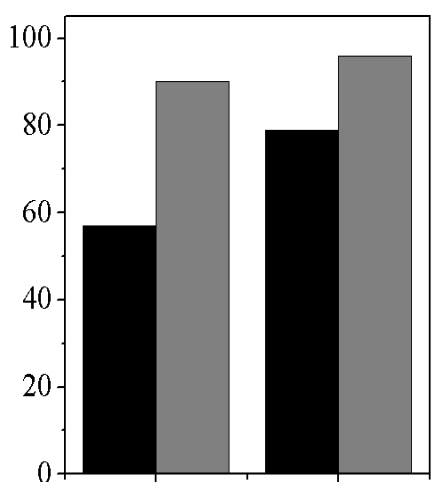

(E)

(F) 
Figure 4

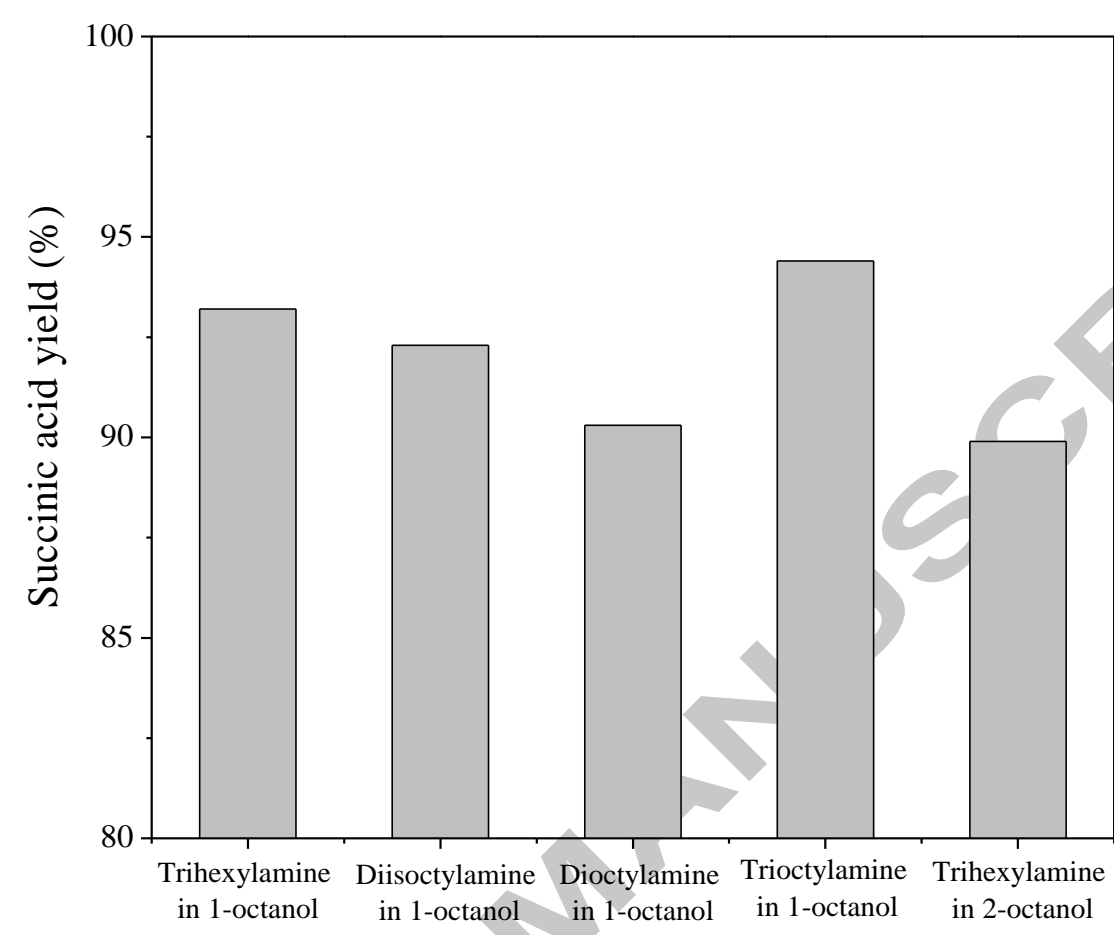

Reactive extraction system 
Figure 5




Table 1 Composition of the two synthetic media (1 and 2) and the two actual fermentation broths (media 3 and 4) used in the DSP

\begin{tabular}{ccccc}
\hline $\begin{array}{c}\text { Component } \\
(\mathbf{g} / \mathbf{L})\end{array}$ & Medium 1 & Medium 2 & Medium 3* & Medium 4* \\
\hline Xylose & 10.2 & 10.2 & 2.8 & 9.3 \\
Succinic acid & 39.3 & 39.3 & 20.3 & 41.2 \\
Lactic acid & 11.1 & 11.1 & 0 & 12.3 \\
Formic acid & 2.0 & 2.0 & 4.6 & 2.0 \\
Acetic acid & 9.6 & 9.6 & 7.6 & 9.9 \\
LS & 0 & 10.0 & 0 & 10.0 \\
\hline
\end{tabular}

*all the acids are present in their corresponding sodium and magnesium salts form 
Table 2 Properties of the different amines and solvents used for the reactive extraction of succinic acid

\begin{tabular}{|c|c|c|c|}
\hline Chemical & $\begin{array}{c}\text { Type of } \\
\text { amine/solvent }\end{array}$ & Boiling point $\left({ }^{\circ} \mathbf{C}\right)$ & $\begin{array}{l}\text { Solubility in water } \\
\qquad\left(25^{\circ} \mathrm{C}\right)\end{array}$ \\
\hline Octylamine & primary & $175-177$ & $0.2 \mathrm{~g} / \mathrm{L}$ \\
\hline Dihexylamine & secondary & $192-195$ & $0.3 \mathrm{~g} / \mathrm{L}$ \\
\hline Dioctylamine & secondary & $297-298$ & $g / L$ \\
\hline Diisooctylamine & secondary & 123 & $6766 \mathrm{mg} / \mathrm{L}$ \\
\hline Tripentylamine & tertiary & $81-83 / 0.2 \mathrm{~mm}$ & insoluble \\
\hline Trihexylamine & tertiary & $263-265$ & No data available \\
\hline Trioctylamine & tertiary & $365-367$ & $0.05 \mathrm{mg} / \mathrm{L}$ \\
\hline Methyldioctylamine & tertiary & $162-165$ / 15 mmHg & No data available \\
\hline 1-butanol & $\begin{array}{c}\text { polar/proton } \\
\text { donating }\end{array}$ & 117.4 & $73 \mathrm{~g} / \mathrm{L}$ \\
\hline 1-Hexanol & $\begin{array}{l}\text { polar/proton } \\
\text { donating }\end{array}$ & $155-159$ & $5.9 \mathrm{~g} / \mathrm{L}\left(20^{\circ} \mathrm{C}\right)$ \\
\hline 1-Octanol & $\begin{array}{l}\text { polar/proton } \\
\text { donating }\end{array}$ & 195 & $0.46 \mathrm{~g} / \mathrm{L}$ \\
\hline 2-Octanol & $\begin{array}{l}\text { polar/proton } \\
\text { donating }\end{array}$ & 178.5 & $1.12 \mathrm{~g} / \mathrm{L}$ \\
\hline $\begin{array}{c}\text { MIBK } \\
\text { (methylisobutylketone) }\end{array}$ & polar/aprotic & 117 & $19.1 \mathrm{~g} / \mathrm{L}\left(20^{\circ} \mathrm{C}\right)$ \\
\hline
\end{tabular}


Table 3 Succinic, lactic and acetic acid extraction yields using different reactive extraction systems at $\mathrm{pH} 2.0$ using medium 4

\begin{tabular}{cccc}
\hline System & $\begin{array}{c}\text { Succinic acid } \\
\text { yield }\end{array}$ & $\begin{array}{c}\text { Lactic acid } \\
\text { yield }\end{array}$ & $\begin{array}{c}\text { Acetic acidy } \\
\text { yield }\end{array}$ \\
\hline Trioctylamine + 1-octanol & 94.0 & 93.2 & 71.8 \\
Trihexylamine + 1-octanol & 93.4 & 90.2 & 70.8 \\
Dioctylamine + 1-octanol & 100.0 & 93.8 & 100.0 \\
Trihexylamine + 1-hexanol & 93.2 & 82.5 & 69.2 \\
Trixexylamine + 1-butanol & 93.8 & 91.4 & 75.4 \\
Trihexylamine + 2-octanol & 79.7 & 67.4 & 53.0 \\
Diisoctylamine + 1-butanol & 97.3 & 100.0 & 86.7 \\
Octylamine + 1-hexanol & 90.6 & 100.0 & 74.0 \\
Dihexylamine + 1-hexanol & 93.4 & 100.0 & 84.1 \\
Dioctylamine + 1-hexanol & 97.4 & 100.0 & 94.2 \\
Tripentylamine + 1-butanol & 88.5 & 100.0 & 78.1 \\
Trioctylamine + 1-hexanol & 98.2 & 100.0 & 93.7 \\
Methyldioctylamine + MIBK & 95.8 & 100.0 & 80.2 \\
Diisoctylamine + dixehylamine + & 97.0 & 100.0 & 86.4 \\
1-octanol + 1-hexanol & 99.0 & 100.0 & 90.7 \\
Diisoctylamine + 1-octanol & & & \\
\hline
\end{tabular}


Table 4 Succinic, lactic and acetic acid extraction yields using different reactive extraction systems at $\mathrm{pH} 5$ using medium 4

\begin{tabular}{ccccc}
\hline System & $\begin{array}{c}\text { Succinic } \\
\text { acid yield }\end{array}$ & $\begin{array}{c}\text { Lactic } \\
\text { acid yield }\end{array}$ & $\begin{array}{c}\text { Formic } \\
\text { acid yield }\end{array}$ & $\begin{array}{c}\text { Acetic } \\
\text { acid yield }\end{array}$ \\
\hline Dioctylamine + 1-octanol & 34.2 & 25.6 & 34.5 & 12.1 \\
Trihexylamine + 2-octanol & 10.7 & 36.0 & 38.9 & 36.4 \\
Trixexylamine + 1-butanol & 11.9 & 46.6 & 46.9 & 43.0 \\
Trihexylamine + 1-hexanol & 12.4 & 36.8 & 41.6 & 39.8 \\
Trioctylamine + 1-octanol & 10.6 & 34.1 & 38.1 & 36.1 \\
Diisoctylamine + 1-octanol & 13.2 & 29.1 & 32.7 & 31.7 \\
Diisoctylamine + 1-butanol & 17.4 & 52.5 & 100.0 & 54.9 \\
Octylamine + 1-hexanol & 14.2 & 39.6 & 100.0 & 37.2 \\
Dihexylamine + 1-hexanol & 14.3 & 67.1 & 100.0 & 76.4 \\
Dioctylamine + 1-hexanol & 22.4 & 34.7 & 100.0 & 40.1 \\
Tripentylamine + 1-butanol & 8.9 & 56.4 & 100.0 & 42.1 \\
Trioctylamine + 1-hexanol & 16.6 & 51.7 & 100.0 & 51.0 \\
$\begin{array}{c}\text { Methyldioctylamine + MIBK } \\
\text { diisoctylamine + }\end{array}$ & 18.7 & 44.9 & 100.0 & 35.7 \\
dixehylamine + 1-octanol + & 3.5 & 7.0 & 100.0 & 47.8 \\
Diisoctylamine + 1-octanol & 14.8 & 19.8 & 100.0 & 53.0 \\
\hline 1-hexanol & & & & \\
\hline
\end{tabular}


Table 5 Characterisation of succinic acid crystals obtained by direct crystallisation with cation-exchange resins (Process 1), by reactive extraction coupled with back extraction using $\mathrm{pH}$ swing (Process 2) and direct crystallisation with cation-exchange resins followed by re-crystallisation (Process 3) with GC-MS and ${ }^{1} \mathrm{H}-\mathrm{NMR}$

\begin{tabular}{|c|c|c|c|c|c|}
\hline Process & Compound & MW & $\begin{array}{c}\% \text { by } \\
\text { GC-MS }\end{array}$ & $\begin{array}{c}\text { Retention } \\
\text { time (min) }\end{array}$ & $\begin{array}{c}\% \text { by }{ }^{1} \mathbf{H}- \\
\text { NMR }\end{array}$ \\
\hline \multirow{9}{*}{ Process 1} & Succinic acid & & & 17.55 & ca. 99 \\
\hline & Acetic acid & & 0.3 & 5.66 & 0.24 \\
\hline & Oxalic acid & 90.03 & 0.06 & 12.03 & \\
\hline & Palmitic acid & 256.43 & 0.80 & 25.80 & \\
\hline & Myristic acid & 228.37 & 0.05 & 23.87 & \\
\hline & Pentadecanoic acid & 242.40 & 0.05 & 24.86 & \\
\hline & Heptadecanoic acid & 270.45 & 0.02 & 26.17 & \\
\hline & Steric acid & 284.48 & 0.07 & 27.58 & \\
\hline & Linoleic acid & - & BLD & 27.23 & \\
\hline \multirow{4}{*}{ Process 2} & Succinic acid & & & 17.47 & ca. 98.5 \\
\hline & Acetic acid & & 0.36 & 5.51 & 0.14 \\
\hline & Palmitic acid & & 0.3 & 25.70 & \\
\hline & Linoleic acid & & $\sim 1.0$ & 27.24 & \\
\hline \multirow{4}{*}{ Process 3} & Succinic acid & & $>99$ & 17.46 & $>99$ \\
\hline & Acetic acid & & BLD & N/A & \\
\hline & Palmitic acid & & 0.3 & 25.71 & \\
\hline & Linoleic acid & & 0.6 & 27.24 & \\
\hline
\end{tabular}




\section{Highlights}

- Five different downstream methods were evaluated for succinic acid separation from SSL-based media

- Reactive extraction using trioctylamine in 1-hexanol coupled with crystallization and direct crystallization with resins resulted in high purity succinic acid crystals

- Re-crystallisation of the succinic acid crystals led to a purity of more than $99 \%$ 